\title{
The atrioventricular junctions in Ebstein malformation
}

\author{
S Y Ho, D Goltz, K McCarthy, A C Cook, M G Connell, A Smith, R H Anderson
}

\begin{abstract}
Objective-To review the anatomical structure of the right atrioventricular junction, including the specialised atrioventricular conduction system, in hearts with Ebstein's malformation, to identify potential substrates for the abnormalities in conduction.

Methods-Five heart specimens representing the morphological spectrum of Ebstein malformation were examined grossly and histologically.

Results-On the endocardial surface, the atrioventricular junction was marked by a faint line in two hearts, and by a small ridge in the other three. Analysis of the right parietal junction in four hearts revealed only two accessory muscular atrioventricular connections. A plane of fibrofatty tissue separated atrial from ventricular myocardium in the right parietal junction in all hearts. The compact atrioventricular node was closer to the coronary sinus than usual. Accessory nodoventricular connections were present in four hearts, while accessory fasciculo-ventricular connections were found in one. The right bundle branch was hypoplastic or absent in four hearts. Conclusions-In this small series, the parietal atrioventricular junction was better developed than previously thought. Structural abnormalities of the atrioventricular conduction system, however, were present. These may account for some of the conduction abnormalities frequently observed with the Ebstein malformation.
\end{abstract}

(Heart 2000;83:444-449)

Keywords: Ebstein's anomaly; atrioventricular node; bundle branch block; Wolff-Parkinson-White syndrome

The malformation first described by Wilhelm Ebstein in $1866^{1}$ is diagnosed on the basis of displacement into the right ventricle of the annular attachment of the septal, and usually the mural, leaflets of the tricuspid valve. Although individual cases can show a wide spectrum of valvar displacement, together with dysplasia of the leaflets, Ebstein's malformation is unmistakable in the necropsy room. This is not always so in the clinical setting, but the frequent association with abnormalities of atrioventricular conduction is a salient feature that aids diagnosis. The classical ECG is well known, showing right atrial hypertrophy, a prolonged PR interval, right bundle branch block, and small QRS voltages over the right chest leads. Left bundle branch block and atrioventricular block are common. ${ }^{2}{ }^{3}$ The reported association of pre-excitation syndromes ranges between $10 \%$ and $23 \%,{ }^{3}$ and most of the accessory pathways identified thus far are located around the orifice of the malformed tricuspid valve. The accessory muscular pathways, often multiple in the same patient, are thought to be caused by faulty formation of the insulating tissues at the atrioventricular junctions. Despite the common occurrence of disorders of atrioventricular conduction, few anatomical studies have examined the conduction system and the state of atrioventricular insulation..$^{5-8}$ Apart from one case studied in detail by Lev et $a l,{ }^{6}$ a systematic analysis of the entire junctional areas, with emphasis on the mechanisms producing insulation, is lacking. In this study, therefore, we reviewed the anatomical structure of the right atrioventricular junction, including the specialised atrioventricular conduction system, in five heart specimens. In order to be able to provide sections of the complete heart in one block of tissue, we specifically selected fetal and infant specimens for our study. These hearts are also more likely to reveal all the potential congenital substrates for abnormal atrioventricular conduction.

\section{Methods}

Four heart specimens from aborted fetuses of gestational ages 15 to 22 weeks and one specimen from an infant of eight days were selected for histological preparation. The hearts showed a range of displacement of the tricuspid valve representative of the known spectrum of Ebstein's malformation, as seen in postnatal life. ${ }^{9}$ Clinical history was not available for any of the cases.

Following morphological examination and fixation, the specimens were photographed to document the level of the right atrioventricular junction and to identify the area of the triangle of Koch. The entire hearts from the fetuses were then processed and blocked in paraffin wax for serial sectioning at $10 \mu \mathrm{m}$ thickness along the four chamber plane. Only the septum and the paraseptal areas of the heart from the infant were processed. Initially, every 25 th section was mounted and stained using Masson's trichrome technique. Further sections were mounted and stained as necessary, following the preliminary studies.

For comparison, we examined the gross morphology of the tricuspid orifice in five normal hearts, all obtained from neonates who died of non-cardiac causes. We probed underneath the septal leaflet to determine the level of its hinge at the septum. From our archives, for further comparisons we retrieved serial histological 
sections of normal hearts that had been obtained from two normal fetuses (23 and 37 weeks' gestation) and four normal infants who died of non-cardiac causes.

\section{Results}

GROSS MORPHOLOGY

The junction between the right atrium and the right ventricle was readily distinguishable in all the normal hearts. On the epicardial aspect, the right coronary artery ran within the fatty tissues of the atrioventricular groove. Within the heart, the hinge of the tricuspid valve provided the landmark to the atrioventricular junction. Along the parietal junction, the ventricular wall turned inwards, resulting in the valvar hinge being positioned 2 to $3 \mathrm{~mm}$ more apically than indicated by the epicardial landmarks. Along the septum, the hinge line was curved, with a dip of up to $2.5 \mathrm{~mm}$ toward the apex in three hearts. All three leafletsseptal, mural, and anterosuperior-were thin and pliable, being anchored by tendinous cords either to the septum or to distinct papillary muscles (fig 1, normal). The region between the atrioventricular junction and the insertions of medial, anterior, and posterior papillary muscles constitutes the inlet portion of the right ventricle, while the free standing muscular infundibulum leading to the pulmonary valve is the outlet. The trabecular component is situated apically. Three zones of apposition within the overall curtain of leaflet tissue, permitting distinction of three leaflets, were seen in all the normal hearts. At the peripheral margins of the zones of apposition (the "commissures"), the adjacent leaflets were supported by fan shaped tendinous cords. The separation between the leaflets was well defined, and the gaps in the free edge reached close to the atrioventricular junction at the commissures, but never extended completely to the annular attachments.

All four malformed hearts from the fetuses had Ebstein's malformation of the tricuspid valve as the sole lesion. As anticipated for fetal hearts, the oval fossa and arterial ducts were patent. In addition to Ebstein's malformation, the heart from the infant had an associated perimembranous ventricular septal defect which excavated toward the outlet portion of the right ventricle (fig 1 , heart 5). The tricuspid valve was malformed in all cases. Dysplasia, defined as thickening of the leaflets and/or abnormalities of the tendinous cords and papillary muscles, or adhesion of leaflet tissue to the ventricular wall, affected the tricuspid valves to greater or lesser degree. ${ }^{10}$ The plane of fatty tissue demarcating the epicardial aspect of the atrioventricular junction was clearly seen in four hearts. In the remaining heart, the epicardial atrioventricular groove was indistinct. This was the only heart in which the inferior wall of the right ventricle was very thin, resembling the atrial wall (fig 1 , heart 1). In this case, the atrioventricular junction could be discerned grossly only after dissection in the shallow atrioventricular groove had revealed the right coronary artery.

In contrast to the normal hearts, it was not possible to distinguish three valvar leaflets in any of the malformed hearts. A small component, corresponding to the septal leaflet, was recognisable in three fetal hearts. In two hearts, this component resembled the "dreigroschen" (three penny piece), or discoid appearance, as had been noted by Ebstein (fig 1, heart 1). Valvar tissue was lacking in the region of the inferior commissure. In the third heart, the septal leaflet was better formed. Its hinge was moderately displaced distal to the atrioventricular junction, where its free edge was short and thickened (fig 1, heart 3). In this heart, the leaflet corresponding to the normal mural leaflet was hinged at the atrioventricular junction and was separated from the septal leaflet by a well formed commissure. In the first two fetal hearts, the "mural" leaflet was severely displaced, being limited to a small flap attached at the junction of the inlet and trabecular components of the right ventricle (fig 1, heart 1). In all three hearts, there was no commissure between the "mural" and anterosuperior leaflets. The anterosuperior leaflet was sail-like and hinged normally at the atrioventricular junction (fig 1, hearts 1 and 3). Distally, the leaflet was attached linearly to a muscular shelf marking the junction between the inlet and apical trabecular components of the right ventricle.

The fourth fetal heart showed the most severe malformation. The trifoliate arrangement of the valvar leaflets was totally effaced. The "septal" and "mural" components were smooth, being devoid of tendinous cords or papillary muscles. There was no separation of leaflets from the ventricular walls, apart from a very small portion toward the ventricular apex. As a consequence, the inlet part appeared like a smooth sac (fig 1, heart 4). The anterosuperior component was the only tissue that resembled a valvar leaflet. It was hinged at the atrioventricular junction, but its distal margin was continuous with the "mural" and "septal" components, with a keyhole between its medial free edge and the ventricular septum as the only communication between inlet and outlet portions.

The septal leaflet was moderately displaced in the heart from the infant. Tissues of the leaflet were found along with a tiny medial papillary muscle (fig 1, heart 5). There was minimal displacement of the mural leaflet.

Within the overall group, owing to the displaced attachments of the septal or mural leaflets, or both, the only part of the atrioventricular junction that was always clearly seen on the endocardial surface was that along the anterosuperior margin. The hinge of the anterosuperior leaflet corresponded to the level of the junction that could be discerned on the epicardial aspect. A faint line was seen along the septal and mural margins of the atrioventricular junction in two hearts. In the other three hearts, a small ridge was visible. Along the septal margin, the line or ridge corresponded to the normal hinge line of the tricuspid valve, an important landmark to the triangle of Koch which contains the atrioventricular node. The other two borders of the triangle, the Eustachian ridge and the coronary sinus, were as clearly seen as in the normal hearts. 

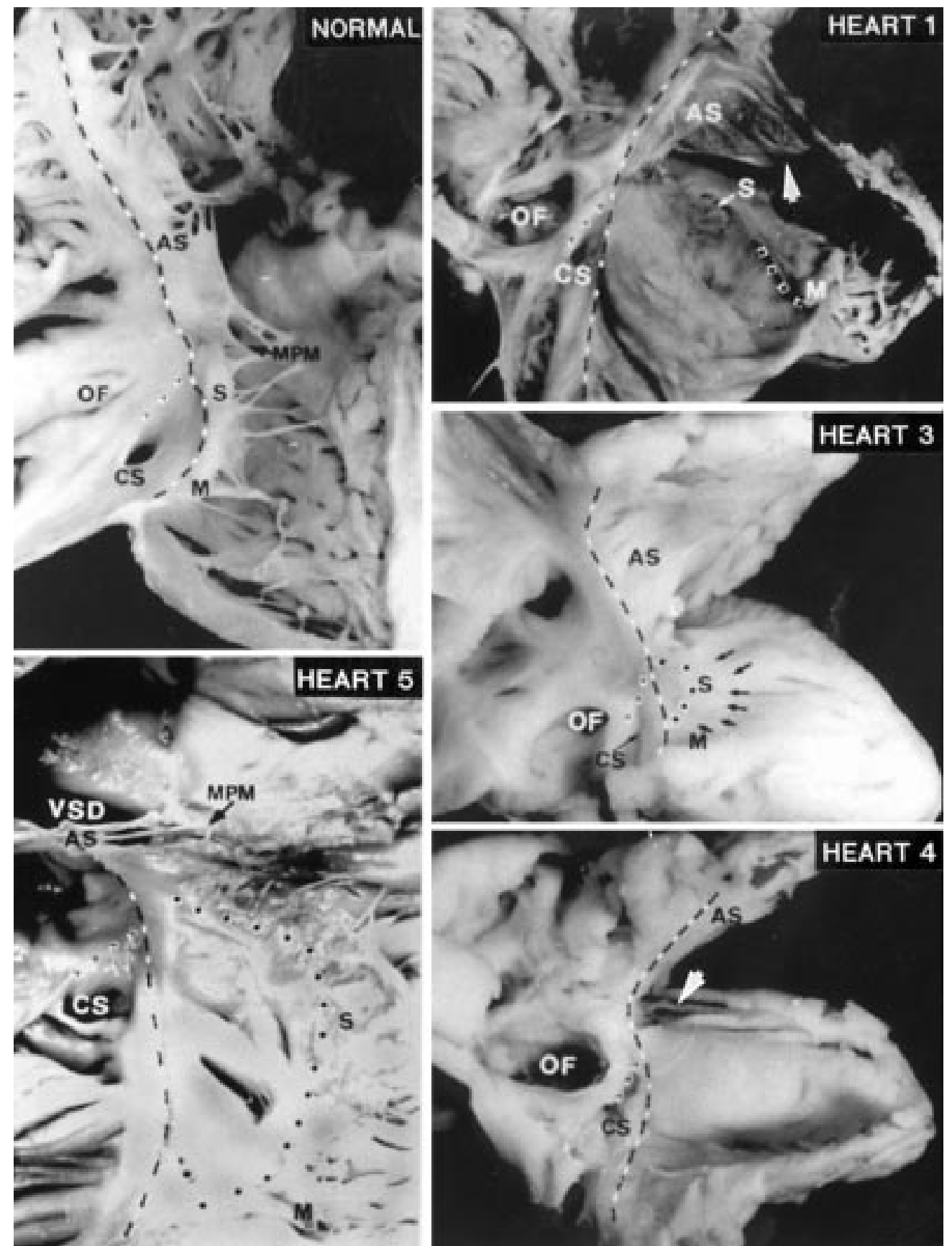

Figure 1 The right atrioventricular junction (broken black and white line) displayed in a normal heart and four malformed hearts. The lateral borders of the triangle of Koch are formed by the atrioventricular junction on the septal aspect and the Eustachian ridge (1) 1). The displaced hinge of the septal $(S)$ and mural $(M)$ leaflets are marked by the dotted line. The anterosuperior leaflet (AS) in heart 1 is attached distally to a muscle shelf (arrowhead). In heart 3, a very pale specimen, the edge of the septal leaflet is indicated by small arrows. Septal and mural leaflets are not formed in heart 4 . The arrow indicates the keyhole before the specimen was cut for display. Heart 5 shows a perimembranous ventricular septal defect (VSD) and a tiny medial papillary muscle (MPM). CS, coronary sinus; OF, oval fossa.

HISTOLOGICAL FINDINGS IN MALFORMED HEARTS In all four fetal hearts with Ebstein's malformation, the parietal right atrioventricular junction, as in the normal heart, was well defined by fibrofatty tissues. The atrioventricular groove was less deep in the hearts with atrialisation of the inferior inlet wall (hearts 1 and 2). In heart 2, there was a small bridge of muscular continuity on the right side which linked ventricular myocardium to a small node-like structure formed at the base of the atrial wall. This short accessory pathway passed through the fibrous tissue of the valvar hinge at the acute cardiac margin. An accessory pathway was found in the obtuse margin of the left atrioventricular junction of heart 1 . This took the form of a bridge of muscle which passed through the fibrous hinge of the mural leaflet of the mitral valve. In the heart from the infant, a strand of accessory muscular tissue extending from a tiny node-like structure was found in the inferior paraseptal part of the right atrioventricular junction. This strand skirted the epicardial side of the fibrous tissue that marked the junction.

As in the normal hearts, the triangle of Koch was delineated on one side by the Eustachian 

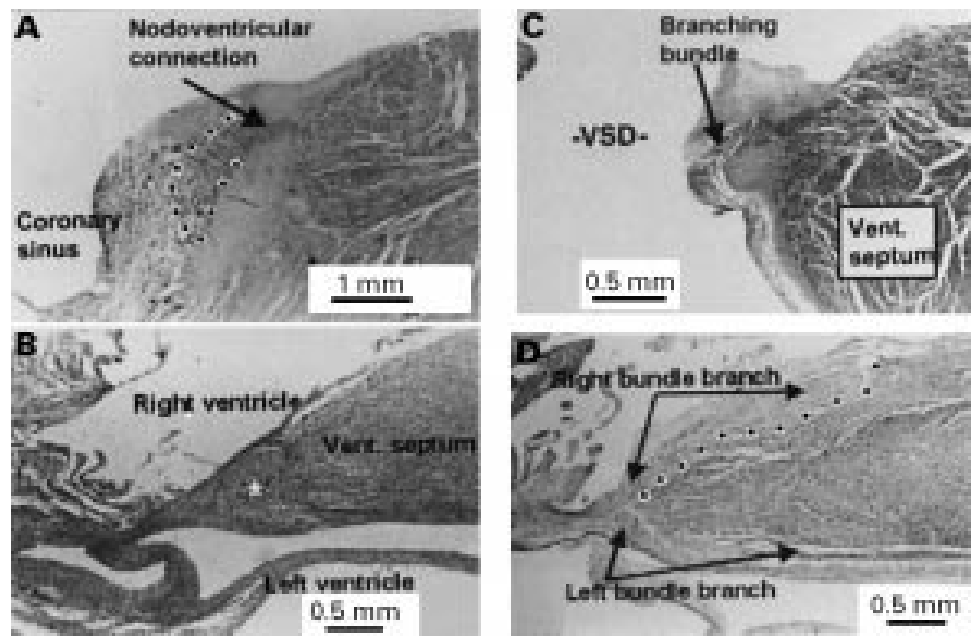

Figure 2 (A) An accessory connection between the atrioventricular node (within dotted line) and ventricular myocardium in heart 4. (B) The same heart shows a large

atrioventricular bundle (white star) which continued into the left bundle branch only. The ventricular bundle branches are seen descending from the septal crest in heart $5(C)$ and in heart 3 (D). VSD, ventricular septal defect.

ridge containing the tendon of Todaro, and on the other side by the tricuspid valve, with the central fibrous body at the apex (fig 1). With displacement of the hinge of the septal leaflet, the atrioventricular junction replaced the valvar border. This plane of fibrous tissue, clearly seen in all the malformed hearts, was
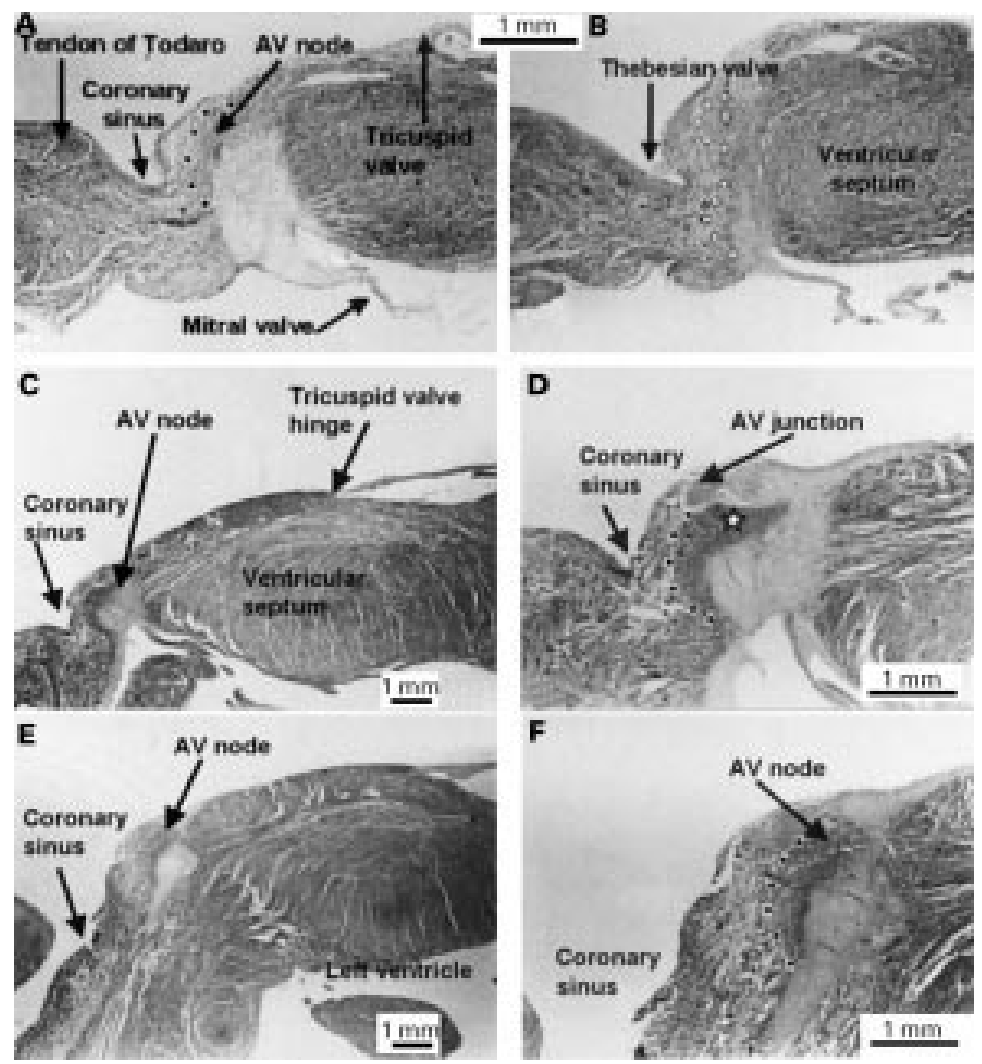

Figure 3 (A) The body of the atrioventricular ( $A V$ ) node (within dotted line) is adjacent to the mouth of the coronary sinus in heart 3. (B) A more inferior section of the same heart shows the inferior nodal extensions (within white dots) at the level of the Thebesian valve. (C) This section from heart 5 shows the atrioventricular $(A V)$ node at a level close to the mouth of the coronary sinus. The hinge of the septal leaflet is displaced from the atrioventricular junction. (D) This magnified view shows the extension (white star) of the conduction tissues from the atrioventricular node into the central fibrous body at the transition to the penetrating bundle. (E) This inferior section also from heart 5 is through the middle of the coronary sinus orifice. It is magnified in $(F)$ to show the continuation of the nodal body at this level. continuous with the inferior atrioventricular groove when traced postero-inferiorly. The compact atrioventricular node, along with its zone of transitional cells, was located in the triangle of Koch. Multiple frond-like incursions of histologically specialised cells into the central fibrous body were seen in three hearts. Continuity with musculature of the septal crest produced strands of nodoventricular muscular connections in hearts 1,3 , and 5 . In heart 4 , an extensive muscular nodoventricular connection was seen at the border between the atrioventricular node and the penetrating bundle (fig 2A). On gross examination, the nodal triangle appeared to be smaller than normal (fig 1).

When the mouth of the coronary sinus was taken as a point of reference in histological sections, the main body of the node was situated closer to the mouth than normal in four hearts (hearts 2-5) (fig 3). Only one of the six normal hearts showed this arrangement. In normal hearts, only the bifurcating inferior extensions of the compact node are found in sections that include the orifice of the coronary sinus. In hearts 4 and 5, the inferior part of the nodal body itself was also seen in this location (fig 3, E, F). When traced superiorly, the atrioventricular node penetrated to become the atrioventricular bundle in all hearts, the transition being marked by entry into the central fibrous body (fig 3, C, D). In heart 2, in association with a small central fibrous body the penetrating bundle was very short. Accessory fasciculoventricular connections between the nonbranching bundle and the crest of the ventricular septum were present in heart 4 . In this heart, the atrioventricular bundle continued into the left bundle branch, without giving origin to a right bundle branch (fig 2B). From its narrow origin, the left bundle branch fanned out as it descended along the septal surface of the left ventricle. The branching bundle was astride the septal crest in the remaining hearts, including the infantile heart with a ventricular septal defect (fig 2C). In hearts 1 and 2, the right bundle branch was narrow, tapered, and terminated a short distance from its origin. The distance was approximately equivalent to the distance to the medial papillary muscle anticipated in the normal hearts. In contrast, a large right bundle branch arising from the branching bundle was seen in subendocardial location in heart 3 (fig 2D). When traced distally to about a third of the distance down the ventricular septum, it terminated abruptly. In this heart, the atrioventricular conduction bundle itself continued superiorly along the crest of the ventricular septum as a dead end tract. The cordlike right bundle branch could be traced to the base of the medial papillary muscle and toward the ventricular apex in heart 5 .

\section{Discussion}

Ever since the description of the index case of Ebstein's malformation, ${ }^{1}$ there have been many studies on the pathological and clinical spectrum of this entity, both in isolation and in association with other intracardiac defects. The key feature in diagnosis is annular attachment 
within the right ventricle, to greater or lesser degree, of the valvar leaflets. ${ }^{5-12}$ It is this feature which aids diagnosis in cross sectional echocardiography. ${ }^{13}$ The other abnormal features include a malformed but normally hinged antero-superior leaflet, a displaced valvar orifice, and almost universal dysplasia of the valvar leaflets. In our present study, to help comparisons we have attempted to name the leaflets of the malformed valve according to conventional terminology, although there is often no clear separation between them. Thus the mural and antero-superior segments of the valvar curtain were continuous in four of the five malformed hearts. The mural leaflet was grossly underdeveloped in the fifth heart. Indeed, this was also the arrangement in the index case. Ebstein ${ }^{1}$ described an extensive membrane in place of the antero-superior and mural leaflets. He also considered that only one leaflet, the septal one, was present, albeit with an abnormal origin below the "annulus fibrosus." It is interesting that, in the illustration provided by Wyss, the abnormal membrane was shown as hinged at the atrioventricular junction. In contrast, the hinge line corresponding to that of the mural leaflet has been displaced in most of the cases subsequently examined at necropsy, ${ }^{814}$ including three of the five cases in our series. Our single case in which displacement was confined to the septal leaflet could be dubbed "micro-Ebstein", ${ }^{15}$ or held to represent a mild form of Ebstein malformation. ${ }^{7}$ It would have been difficult to differentiate this case from the usual slightly scooped hinge line found in normal hearts had it not been for the abnormally extensive antero-superior leaflet and the overall dysplasia of the valvar leaflets. The term "microEbstein," moreover, is probably misleading, as it detracts from the severity of the defect, which can be accompanied by potentially life threatening conduction defects. ${ }^{75}$

Apart from a few studies focusing on the arrangement of the atrioventricular conduction system in "isolated" Ebstein's malformation, only the study by Lev et al has described the parietal atrioventricular junction. ${ }^{6}$ On gross dissection, this area gives the impression of direct atrial and ventricular myocardial continuity, especially along the mural quadrant. In order to account for the prevalence of accessory pathways, it is presumed that the parietal atrioventricular junction has an inherent weakness, providing "holes" for myocardial bridges. ${ }^{16}$ On the contrary, as confirmed histologically by Lev et $a l^{6}{ }^{6}$ and by our study, such muscular continuity does not exist. In our cases, the parietal atrioventricular junction was well formed. A fibrofatty tissue plane, albeit small in some areas, always intervened to provide electrical insulation between atrial and ventricular myocardium. We found only one accessory right parietal connection among our four hearts that were sectioned in their entirety, although one left sided connection was also found. An anterior connection found in one of the cases examined by Becker and co-workers ${ }^{17}$ was more reminiscent of the configuration now known to be associated with "Mahaim" physi- ology. In their case, the accessory muscular connection again took origin from an atrial node, but continued as a long bundle of specialised myocardium which was insulated as it descended within the myocardium of the parietal wall. If traced in its entirety, it could have connected with ramifications of the right bundle branch. Yet another arrangement was found in the case examined by Lev et al. ${ }^{6}$ The accessory muscular pathway located in the parietal wall was again long, but it coursed along the anterior quadrant of the atrioventricular groove to the acute margin, sending multiple small branches to the ventricular and atrial walls. Accessory pathways have also been described in Ebstein's malformation associated with congenitally corrected transposition. ${ }^{18-20}$ These varied from broad bands to multiple thin pathways that perforated the fibrous annulus, as in the case described by Symons and coworkers, ${ }^{18}$ or extended epicardially close to the fibrous plane of insulation to reach the ventricular wall.

As suggested by recent reports on radiofrequency ablation of accessory pathways in patients with Ebstein's malformation, it appears that some pathways are long, reaching a fair distance apically along the ventricular wall. ${ }^{21}$ These are thought to be associated with atrialisation of the ventricular inlet. An alternative explanation is that they represent the so called "atriofascicular tracts" which extend apically to connect with the right bundle branch, and which produce "Mahaim" physiology. Certainly, the structure of the muscular accessory atrioventricular pathways to be found in Ebstein malformation requires still further elucidation should hearts come to necropsy from patients known to have had pre-excitation.

Previous accounts of the atrioventricular conduction system ${ }^{67}$ have revealed muscular continuity between the conduction axis and the crest of the muscular ventricular septum in four cases. The heart examined by Lev et al revealed a connection between the origin of the right bundle branch and the right side of the septum. ${ }^{6}$ Rossi and Thiene ${ }^{7}$ described unusual septal pathways in their three cases of mild Ebstein malformation. In all cases, the accessory muscular atrioventricular connections passed from the right side of the atrioventricular node, and penetrated through a gap in the right margin of the fibrous insulating plane. One case was unique in that the accessory pathway anastomosed with an accessory nodoventricular connection before reaching ordinary ventricular myocardium. In this case ${ }^{7}$ the investigators concluded that the accessory muscular connections persisted as a result of limited maturation of the central fibrous body, which failed to abolish fetal connections. Such changes were not seen in our hearts. Accessory frond-like connections, however, are frequently seen in normal fetal and neonatal hearts, and were the original "paraspecific" fibres described by Mahaim. ${ }^{22}$ These structures were also present in our malformed hearts. Their potential role as significant bypass tracts remains to be resolved, as they are seldom found with such abundance in mature hearts. 
When the accessory connection is broad and band-like, as in our fourth heart, it is tempting to assume that it is more likely to persist into infancy and beyond, then being capable of producing pre-excitation.

As suggested by previous studies, ${ }^{8}$ the landmark to the location of the atrioventricular node in the setting of Ebstein's malformation remains the triangle of Koch. Even with displacement of the hinge line of the septal leaflet of the tricuspid valve, the valvar margin - representing the atrioventricular junction - was clear on gross examination in two of our four specimens. On histological examination, the margin was clearly marked in all specimens by the fibrofatty plane of tissues that extended antero-superiorly from the inferior atrioventricular groove toward the apex of the triangle at the central fibrous body. In three hearts, the location of the compact atrioventricular node was closer to the orifice of the coronary sinus than in normal hearts. As the penetrating bundle was normally located, the node was either more extensive or, conversely, the nodal triangle was smaller. Further studies making correlations with aging are needed to clarify this observation. This feature is particularly relevant because interventions to cure atrial flutter, atrioventricular nodal reentrant tachycardia, or accessory atrioventricular pathways may all be carried out in the vicinity of the nodal triangle. ${ }^{23} 24$

Despite the frequent occurrence of right bundle branch block, structural abnormalities have seldom been reported in the cases examined histologically. A slightly anomalous course of the right bundle has been noted in three cases, ${ }^{8}$ but none showed interruption. In one textbook, ${ }^{25}$ a general comment is made that in some of the cases studied the right bundle branch "simply fizzled out." In our specimens, the right bundle branch was narrow and short in the two hearts that had minimally formed septal leaflets. A thick but short right bundle branch was found in the heart with moderate displacement of the septal leaflet. A regular right bundle branch was found only in the heart from the infant; in this heart, the septal leaflet, although displaced, was formed, and there was a tiny medial papillary muscle. In the remaining heart, the right bundle was absent, and there was practically no formation of the septal leaflet. The right bundle branch, therefore, was abnormal or underdeveloped in three and absent in one of our five cases of Ebstein's malformation. Its development seemed to be related to the formation of the septal leaflet and the medial papillary muscle.

\section{LIMITATIONS OF THE STUDY}

Our study was confined to only five cases, all fetal and infant hearts. We were unable to make comparisons with adolescent or adult hearts, as their larger size poses practical problems for histological preparations. Clinical information was not available for any of the fetal cases. There was insufficient information in the case of the infant to make any correlations with structural anomalies of the conduction system. Our small series, nevertheless, represented the range of severity of the gross malformation. It showed that, while the atrioventricular junction was well developed, structural abnormalities of the atrioventricular conduction system were common. The close relation of the atrioventricular node to the orifice of the coronary sinus is worthy of note. Whether this relation is maintained in the older child or adult remains to be determined. This has implications for surgical or ablation procedures in the inferior paraseptal area.

SYH and RHA are supported by the British Heart Foundation together with the Joseph Levy Foundation. MGC is supported by the Endowment Fund of the Royal Liverpool Children Hospitals. During this study, DG was a visiting medical student pitals. During this study, DG was a visit
from the University of Bonn, Germany.

1 Ebstein W. Ueber einen sehr seltenen Fall von Insuffizienz der Valvula tricuspidalis, bedingt durch eine angeborene hochgradige Missbildung derselben. Arch fur Anat u Physiol 1866:238-54

2 Kastor JA, Bruce N, Goldreyer N, et al. Electrophysiologic characteristics of Ebstein's anomaly of the tricuspid valve. Circulation 1975;52:987-95.

3 Watson H. Natural history of Ebstein's anomaly of tricuspid valve in childhood and adolescence. Br Heart $\mathcal{F} 1974 ; 36$ : $417-27$

4 Van Lingen B, Bauersfeld SR. The electrocardiogram in Ebstein's anomaly of the tricuspid valve. Am Heart f 1955; 50:13-23.

5 Yater WM, Shapiro MJ. Congenital displacement of the tricuspid valve (Ebstein's disease): review and report of a case with electrocardiographic abnormalities and detailed histologic study of the conduction system. Ann Intern Med 1937;11:1043-62.

6 Lev M, Gibson S, Miller RA. Ebstein's disease with Wolff-Parkinson-White syndrome. Am Heart $\mathcal{F}$ 1955;49: 724-41.

7 Rossi L, Thiene G. Mild Ebstein's anomaly associated with supraventricular tachycardia and sudden death: clinicomorpholo features in 3 patients. Am 7 Cardiol 1984;53: 332-4.

8 Anderson KR, Zuberbuhler JR, Anderson RH, et al. Morphologic spectrum of Ebstein's anomaly of the heart. Mayo Clin Proc 1979;54:174-80.

9 Schrieber C, Cook A, Ho SY, et al. Morphologic spectrum of Ebstein's malformation: revisitation relative to surgical repair. F Thorac Cardiovasc Surg 1999;117:148-55.

10 Becker AE, Becker MJ, Edwards JE. Pathologic spectrum of dysplasia of the tricuspid valve. Arch Pathol 1971;91:16778 .

11 Genton E, Blount G. The spectrum of Ebstein's anomaly. Am Heart f 1967;73:395-423.

12 Leung MP, Baker EJ, Anderson RH, et al. Cineangiographic spectrum of Ebstein's malformation: its relevance to clinical presentation and outcome. $7 \mathrm{Am}$ Coll Cardiol 1988; clinical present

13 Shiina A, Seward JB, Edwards WD, et al. Two-dimensional echocardiographic spectrum of Ebstein's anomaly: detailed anatomic assessment. $\mathcal{F} \mathrm{Am}$ Coll Cardiol 1984;3:356-70.

14 Edwards JE. Pathologic features of Ebstein's malformation Edwards JE. Pathologic features of Ebstein's malform
of the tricuspid valve. Mayo Clin Proc 1953;28:89-94

15 Thiene G, Pennelli N, Rossi L. Cardiac conduction system abnormalities as a possible cause of sudden death in young athletes. Hum Pathol 1983;14:704-9.

16 Verduyn Lunel AA. Significance of annulus fibrosus of heart in relation to $\mathrm{AV}$ conduction and ventricular activation in cases of Wolff-Parkinson-White syndrome. Br Heart $\mathcal{f}$ 1973;34:1263-71.

17 Becker AE, Anderson RH, Durrer D, et al. The anatomical substrate of Wolff-Parkinson-White syndrome. A clinicopathologic correlation in seven patients. Circulation 1978; 57:870-9.

18 Symons JC, Shinebourne EA, Joseph MC, et al. Criss-cross heart with congenitally corrected transposition: report of a case with d-transposed aorta and ventricular preexcitation. Eur f Cardiol 1977;5:493-505.

19 Bharati S, Rosen K, Steinfield L, et al. The anatomic substrate for preexcitation in corrected transposition. substrate for preexcitation
Circulation 1980;62:831-42.

20 Becker AE, Anderson RH. The Wolff-Parkinson-White syndrome and its anatomical substrates. Anat Rec 1981;20: 169-77.

21 Cappato R, Schluter M, Weiss C, et al. Radiofrequency current catheter ablation of accessory atrioventricular pathways in Ebstein's anomaly. Circulation 1996;94:376-83.

22 Mahaim I. Kent's fiber and the AV paraspecific conduction through the upper connection of the bundle of His-Tawara. Am Heart f 1947;33:651-3.

23 Okishige K, Azegami K, Goseki Y, et al. Radiofrequency ablation of tachyarrhythmias in patients with Ebstein's anomaly. Int $\mathcal{f}$ Cardiol 1997;60:171-80.

24 Reich JD, Auld D, Hulse E, et al. The pediatric radiofrequency ablation registry's experience with Ebradiofrequency ablation registry's experience with Eb-
stein's anomaly. f Cardiovasc Electrophysiol 1998;9:1370-7.

25 Anderson RH, Macartney FJ, Shinebourne EA, et al. Paediatric cardiology, vol 2. Edinburgh: Churchill Livingstone, 1987:724. 